\title{
Study on the surgical treatment of carpian tunnel syndrome using the WALANT method
}

\section{Studiu asupra tratamentului chirurgical al sindromului de tunel carpian prin utilizarea metodei WALANT}

\author{
Cătălin BEJINARIU ${ }^{1}$, Carmen GIUGLEA ${ }^{2}$, Silviu MARINESCU ${ }^{1}$ \\ ${ }^{1}$ Secția de Chirurgie Plastică şi Microchirurgie Reconstructivă, \\ Spitalul Clinic de Urgență „Bagdasar-Arseni“, București, România \\ ${ }^{2}$ Secția de Chirurgie Plastică, Estetică şi Microchirurgie Reconstructivă, \\ Spitalul Clinic de Urgență „Sf. Ioan“, București, România
}

\begin{abstract}
The study aims to present the advantages and disadvantages of the WALANT (Wide Awake Local Anesthesia No Tourniquet) method during the therapeutic protocol of the carpal tunnel syndrome.

In order to perform the study the data obtained from the patients who have benefited from surgical treatment in the "Bagdasar-Arseni" Emergency Clinical Hospital were monitored, the analysis being performed on a batch of 41 patients admitted to the plastic surgery department during the period January 2018 - October 2019.

The results show that the use of the WALANT method contributes to the increase of the patients' satisfaction regarding the postoperative result, also being associated with a significant decrease of the overall treatment cost and the global risk level specific to this surgical intervention.

Including the WALANT method in the therapeutic protocol of patients diagnosed with carpal tunnel syndrome is a very good option, being associated with performance indicators that have improved values compared to those obtained by the usage of loco-regional anesthesia involving tourniquets.
\end{abstract}

Keywords: carpal tunnel decompression, WALANT method, hand surgery

\section{REZUMAT}

Studiul de față își propune să prezinte avantajele și dezavantajele utilizării metodei WALANT (Wide Awake Local Anesthesia No Tourniquet) in cadrul protocolului terapeutic al sindromului de tunel carpian.

Pentru realizarea studiului au fost monitorizate datele obținute de la pacienții care au beneficiat de tratament chirurgical în cadrul Spitalului Clinic de Urgență „Bagdasar-Arseni“, analiza fiind realizată pe un lot de 41 de pacienți internați în secția de chirurgie plastică în intervalul ianuarie 2018 -octombrie 2019.

Rezultatele arată că utilizarea metodei WALANT contribuie la creșterea gradului de satisfacție a pacienților cu privire la rezultatul postoperator, fiind, de asemenea, asociată cu o reducere semnificativă a costului total al tratamentului și a nivelului global al gradului de risc specific acestei intervenții chirurgicale.

Includerea metodei WALANT în protocolul terapeutic al pacienților diagnosticați cu sindromul de tunel carpian este o opțiune foarte bună, fiind asociată cu indicatori de performanță superiori celor obținuți prin utilizarea anesteziei loco-regionale care implică utilizarea benzilor hemostatice.

Cuvinte cheie: decomprimarea tunelului carpian, metoda WALANT, chirurgia mâinii 


\section{INTRODUCERE}

Metoda WALANT (Wide Awake Local Anesthesia No Tourniquet) permite realizarea intervențiilor chirurgicale la nivelul mâinii și antebrațului prin utilizarea principiilor farmacologice ale lidocainei și adrenalinei. Protocolul anestezic are ca elemente de bază blocarea durerii prin utilizarea lidocainei și realizarea unui câmp operator de calitate pornind de la principiile vasoconstrictoare ale adrenalinei (1). Literatura de specialitate abundă de materiale dedicate înțelegerii avantajelor și dezavantajelor utilizării acestei tehnici anestezice în cadrul protocoalelor de tratament dedicate chirurgiei mâinii (2).

Contextul realizării studiului este caracterizat de existența la nivel național a unei game extrem de variate de abordări terapeutice, tratamentul chirurgical deschis fiind realizat cu anestezie generală, loco-regională și locală (3). Tratamentul endoscopic al sindromului de tunel carpian nu beneficiază de o popularitate crescută în România, deși literatura de specialitate prezintă date încurajatoare cu privire la avantajele utilizării acestei tehnici (4). Gradul redus de vizibilitate al structurilor anatomice vizate reprezintă, fără doar și poate, principalul dezavantaj al abordării endoscopice.

\section{MATERIALE ŞI METODĂ}

Studiul are la bază datele obținute în urma efectuării tratamentului chirurgical pentru 41 de pacienți internați în cadrul Spitalului Clinic de Urgență „Bagdasar-Arseni“ în intervalul ianuarie 2018 - octombrie 2019, pacienți care au beneficiat de decomprimare chirurgicală prin utilizarea tehnicii WALANT. Pentru realizarea intervenției chirurgicale, pacienții au fost internați în regim de spitalizare continuă, investigațiile paraclinice efectuate fiind reprezentate de: hemogramă, leucogramă, transaminaze, uree, creatinină, glicemie, INR, PT și APTT. Pacienții incluși în lot nu au prezentat în istoric reacții alergice la lidocaină sau alte substanțe medicamentoase. În ceea ce privește limitele de vârstă, cel mai tânăr pacient inclus în studiu a avut 37 de ani, pentru ca extrema superioară de vârstă să fie de 72 de ani.

Pentru aprecierea rezultatelor au fost analizate: durata medie a intervenției chirurgicale, rata complicațiilor postoperatorii, gradul de satisfacție a pacienților cu privire la rezultatul postoperator și probabilitatea de recomandare a procedurii de către pacient.

În ceea ce privește protocolul terapeutic, acesta a inclus realizarea anesteziei locale prin injecta- rea unei soluții anestezice alcătuite din lidocaină și adrenalină $(10: 0,1)$ la nivelul feței volare a turneului carpian, urmată de secționarea ligamentului transvers al carpului prin intermediul unei incizii cutanate cu lungimea de aproximativ $2 \mathrm{~cm}$ (Figura 1).

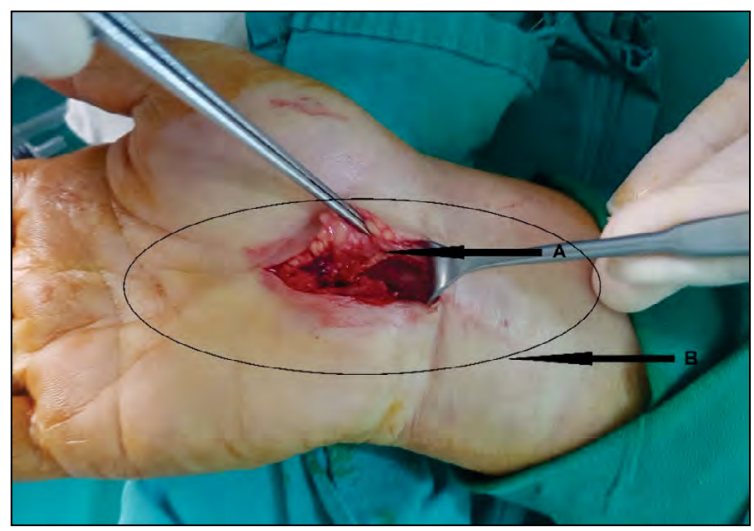

FIGURA 1. Decomprimarea tunelului carpian - aspect intraoperator. A - Secționarea ligamentul transvers al carpului pentru explorarea nervului median;

$B$-Zonă de vasoconstricție evidențiată prin aspectul palid al tegumentului

\section{REZULTATE}

Durata medie de spitalizare a fost de 24 de ore, intervalul mediu necesar instalării efectului anestezic fiind de 23 de minute, etapa chirurgicală întinzându-se în medie pe durata a 20 de minute. Intervalul scurs de la debutul simptomatologiei până în momentul efectuării tratamentului chirurgical a variat între 9 luni și 7 ani, cazurile neglijate fiind asociate cu atrofie marcată a eminenței tenare (Figura 2).

În ceea ce privește rata complicațiilor, formarea hematomului a fost identificată în cazul a 3 pacienți, fiind cea mai frecventă complicație, urmată de dehiscența plăgii, în 2 cazuri, și infecția superficială asociată unui pacient diagnosticat cu diabet zaharat tip 2.

Gradul de satisfacție a pacienților cu privire la rezultat și probabilitatea de recomandare a procedurii au prezentat valori peste media specifică decomprimării tunelului carpian, 9,2, respectiv 9,7.

Aspectul estetic al cicatricii postoperatorii a fost apreciat de majoritatea pacienților ca fiind foarte bun (Figura 3), rezultate nefavorabile obținându-se în cazul a 3 pacienți care au asociat complicații postoperatorii de tip dehiscență și infecție superficială.

\section{DISCUȚII}

Literatura de specialitate arată că tratamentul chirurgical al sindromului de tunel carpian realizat 

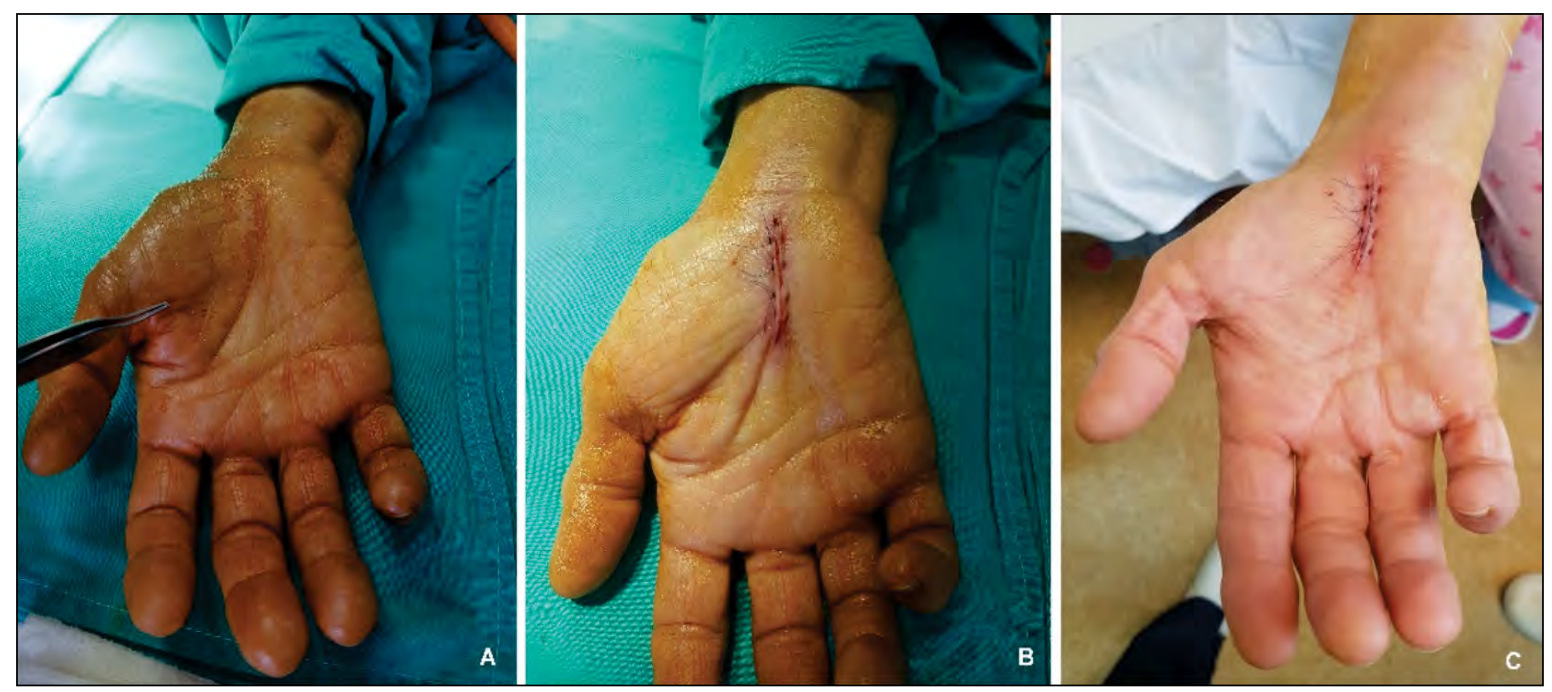

FIGURA 2. Sindrom de tunel carpian cu istoric de 5 ani. A - Atrofie marcată a eminenței tenare. B-Aspect postoperator la finalul decomprimării. C-Aspect local la 24 de ore de la efectuarea intervenției chirurgicale

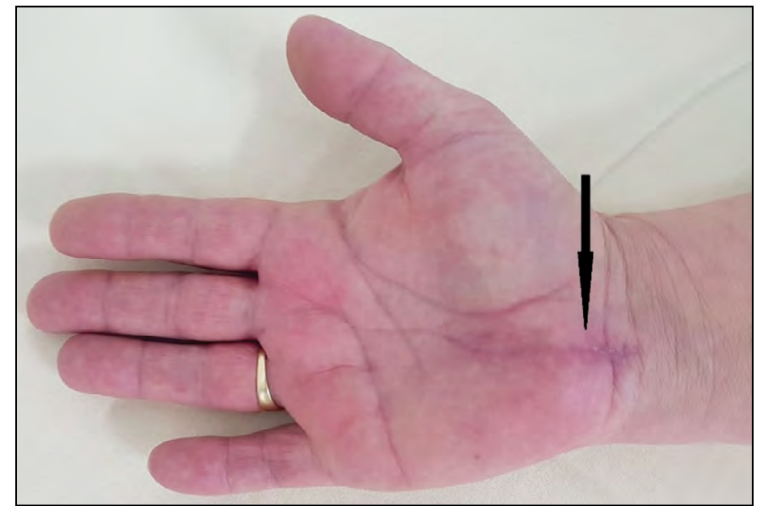

FIGURA 3. Aspect postoperator la 30 de zile

prin utilizarea anesteziei loco-regionale tip bloc Bier se asociază cu rezultate foarte bune din punctul de vedere al recuperării vitezei de conducere nervoasă și cu un nivel crescut al gradului de satisfacție a pacienților cu privire la rezultatul postoperator (5-8). Cu toate acestea, trebuie menționat că utilizarea benzilor hemostatice contribuie în mod semnificativ la scăderea gradului de confort al procedurii, tehnica asociindu-se, de asemenea, cu un risc crescut al scăderii valorilor tensionale în momentul îndepărtării benzii hemostatice. Aceste elemente își exercită efectul asupra probabilității de recomandare a procedurii de către pacienți în sensul scăderii valorii medii a acestui parametru.

Realizarea decomprimării tunelului carpian în condițiile utilizării anesteziei generale reprezintă o opțiune de rezervă dedicată unor cazuri atent selecționate, fiind cu precădere soluția pentru rezolvarea unor traumatisme complexe care, în cadrul protocolului terapeutic, impun și decomprimarea regiunii carpiene (9-12).

Fezabilitatea tehnicii WALANT este recunoscută în cadrul comunității științifice dedicate chirurgiei mâinii, această abordare prezentând multiple avantaje în cazul tratamentului: maladiei Dupuytren, degetului în resort, tumorilor mâinii, malformațiilor digitale, fracturilor oaselor metacarpiene și ale falangelor. Capacitatea de secționare a ligamentului transvers al carpului în condițiile analgeziei complete și vizualizarea tuturor structurilor anatomice de la acest nivel în absența benzilor hemostatice constituie avantaje incontestabile ale utilizării acestei tehnici în cadrul protocolului terapeutic al sindromului de tunel carpian.

Utilizarea adrenalinei în cadrul protocolului WALANT impune $o$ atenție sporită a echipei chirurgicale în ceea ce privește realizarea hemostazei. Proprietățile farmacologice vasoconstrictoare pot crea premisele apariției complicațiilor postoperatorii de tip hematom prin realizarea unei hemostaze insuficiente intraoperator (13-14).

Profilul crescut de siguranță a tehnicii WALANT și rata mică a complicațiilor asociate tratamentului sindromului de tunel carpian prin utilizarea acestei tehnici sunt elemente de bază care permit realizarea acestui tip de tratament în regim ambulator, pacientul putând să părăsească clinica la câteva ore de la efectuarea intervenției chirurgicale (15).

\section{CONCLUZII}

Realizarea tratamentului chirurgical al sindromului de tunel carpian prin utilizarea tehnicii WALANT reprezintă o soluție fermă, asociată cu un nivel crescut al gradului de satisfacție a pacientului, cu o rată redusă a complicațiilor și cu o probabilitate crescută de recomandare a procedurii chirurgicale de către pacient.

Conflict of interest: none declared Financial support: none declared 


\section{BIBLIOGRAFIE}

1. Nikkhah D, Ruston J, Pearl R, Blair J. WALANT carpal tunnel release: Technical considerations and pain outcomes. Journal of Plastic, Reconstructive \& Aesthetic Surgery. 2019;72(9): 1576-1606.

2. Kang SW, Park HM, Park JK, Jeong HS, Cha JK, Go BS, Min KT. Open cubital and carpal tunnel release using wide-awake technique: Reduction of postoperative pain J Pain Res. 2019; 12: 2725-2731.

3. Larsen MB, Sorensen Al, Crone KL, Weis T, Boeckstyns ME. Carpal tunnel release: $A$ randomized comparison of three surgical methods. J Hand Surg Eur Vol. 2013;38: 646-650.

4. Kang HJ, Koh IH, Lee TJ, Choi YR. Endoscopic carpal tunnel release is preferred over mini-open despite similar outcome: A randomized trial. Clin Orthop Relat Res. 2013;471: 1548-1554.

5. Pourmemari MH, Heliövaara M, ViikariJuntura E, Shiri R. Carpal tunnel release: Lifetime prevalence, annual incidence, and risk factors. Muscle\&Nerve. 2018; 58(4):497-502.

6. Sayegh ET, Strauch RJ. Open versus Endoscopic Carpal Tunnel Release: A
Meta-analysis of Randomized Controlled Trials. R.J. Clin Orthop Relat Res. 2015; 473(3): 1120-1132.

7. Bejinariu C, Apostolescu I, Marinescu S. Tratamentul cicatricilor postcombustionale de la nivelul sânului. Romanian Journal of Medical Practice. 2019;14(1):62-65.

8. Aslani HR, Alizadeh K, Eajazi A, Karimi A, Karimi MH, Zaferani Z, Hosseini Khameneh SM. Comparison of carpal tunnel release with three different techniques. Clin Neurol Neurosurg. 2012;114: 965-968.

9. Ejiri S, Kikuchi S, Maruya M, Sekiguchi Y, Kawakami R, Konno S. Short-term results of endoscopic (Okutsu method) versus palmar incision open carpal tunnel release: A prospective randomized controlled trial. Fukushima J Med Sci. 2012;58: 49-59.

10. Bejinariu CG, Marinescu SA, Enescu DM. The Romanian National Breast Reconstruction Program - Results and Conclusions after 5 Years. Modern Medicine. 2019;26(1):23-30.

11. Raducu L, Avino A, Cozma CN, BalcangiuStroescu AE, Timofte D, Tanasescu Md, Balan DG, Jecan CR, Ionescu D. Open Carpal Tunnel Release: Performed Axillary
Brachial Plexus Block Versus Wide Awake. Rev. Chim. (Bucharest). 2019; 70(5): 1637-1638.

12. Bejinariu C, Giuglea C, Marinescu S. Research on the surgical treatment of the trigger. Romanian Medical Journal. 2019; 66(3): 264-267.

13. Mckee DE, Lalonde DH, Thoma A, Dickson L. Achieving the Optimal Epinephrine Effect in Wide Awake Hand Surgery using Local Anesthesia without a Tourniquet. Hand 2015; 10(4): 613-615.

14. Bejinariu C, Giuglea C, Marinescu S. Complex facial reconstruction using local anesthesia - case presentation. Romanian Journal of Medical Practice. 2019; 14(3): 321-324.

15. Lalonde D, Martin A. Tumescent Local Anesthesia for Hand Surgery: Improved Results, Cost Effectiveness, and WideAwake Patient Satisfaction. Arch Plast Surg. 2014; 41(4):312-316. 